\title{
Activity of the cyclooxygenase 2-prostaglandin-E prostanoid receptor pathway in mice exposed to house dust mite aeroallergens, and impact of exogenous prostaglandin $\mathbf{E}_{\mathbf{2}}$ Aida Herrerias ${ }^{1}$, Rosa Torres ${ }^{1,2,3}$, Mariona Serra1 ${ }^{1}$, Alberto Marco ${ }^{4}$, Laura Pujols 2,3 , César Picado ${ }^{2,3}$ and Fernando de Mora*1
}

Address: ${ }^{1}$ Department of Pharmacology, Universitat Autònoma de Barcelona, Barcelona, Spain, ${ }^{2}$ Department of Pneumology and Respiratory Allergy, Hospital Clínic, IDIBAPS, Universitat de Barcelona, Spain, ${ }^{3}$ CIBER [Centro de Investigación Biomédica en Red] de Enfermedades Respiratorias, Spain and ${ }^{4}$ Department of Animal Pathology, Universitat Autònoma de Barcelona, Barcelona, Spain

Email: Aida Herrerias - aida.herrerias@uab.cat; Rosa Torres - rosa.torres@uab.cat; Mariona Serra - mariona.serra@uab.cat; Alberto Marco - alberto.marco@uab.cat; Laura Pujols - lpujols@clinic.ub.es; César Picado - cpicado@uab.edu; Fernando de Mora* - fernando.demora@uab.cat

* Corresponding author

Published: 30 October 2009

Journal of Inflammation 2009, 6:30 doi: 10.1 186/1476-9255-6-30
Received: 4 May 2009

Accepted: 30 October 2009

This article is available from: http://www.journal-inflammation.com/content/6/1/30

(c) 2009 Herrerias et al; licensee BioMed Central Ltd.

This is an Open Access article distributed under the terms of the Creative Commons Attribution License (http://creativecommons.org/licenses/by/2.0), which permits unrestricted use, distribution, and reproduction in any medium, provided the original work is properly cited.

\begin{abstract}
Background: Prostaglandin $\mathrm{E}_{2}\left(\mathrm{PGE}_{2}\right)$, experimentally administered to asthma patients or assayed in murine models, improves allergen-driven airway inflammation. The mechanisms are unknown, but fluctuations of the endogenous cyclooxygenase (COX)-2/prostaglandin/E prostanoid (EP) receptor pathway activity likely contribute to the clinical outcome. We analyzed the activity of the pathway in mice sensitized to aeroallergens, and then studied its modulation under exogenous $\mathrm{PGE}_{2}$.
\end{abstract}

Methods: Mice were exposed to house dust mite (HDM) aeroallergens, a model that enable us to mimic the development of allergic asthma in humans, and were then treated with either subcutaneous $\mathrm{PGE}_{2}$ or the selective EPI/3 receptor agonist sulprostone. Simultaneously with airway responsiveness and inflammation, lung COX-2 and EP receptor mRNA expression were assessed. Levels of $\mathrm{PGE}_{2}, \mathrm{PGI}_{2}, \mathrm{PGD}_{2}$ were also determined in bronchoalveolar lavage fluid.

Results: HDM-induced airway hyperreactivity and inflammation were accompanied by increased COX-2 mRNA production. In parallel, airway $\mathrm{PGE}_{2}$ and $\mathrm{PGI}_{2}$, but not $\mathrm{PGD}_{2}$, were upregulated, and the EP2 receptor showed overexpression. Subcutaneous $P_{G} E_{2}$ attenuated aeroallergen-driven airway eosinophilic inflammation and reduced endogenous $\mathrm{PGE}_{2}$ and $\mathrm{PGI}_{2}$ production. Sulprostone had neither an effect on airway responsiveness or inflammation nor diminished allergen-induced COX-2 and $\mathrm{PGE}_{2}$ overexpression. Finally, lung EP2 receptor levels remained high in mice treated with $\mathrm{PGE}_{2}$, but not in those treated with sulprostone.

Conclusion: The lung COX-2/PGE $/$ /EP2 receptor pathway is upregulated in HDM-exposed mice, possibly as an effort to attenuate allergen-induced airway inflammation. Exogenous $\mathrm{PGE}_{2}$ downregulates its endogenous counterpart but maintains EP2 overexpression, a phenomenon that might be required for administered $\mathrm{PGE}_{2}$ to exert its protective effect. 


\section{Background}

Allergic asthma is a common inflammatory disease of the airway, and long-term therapy is aimed at counteracting episodes of bronchospasm and reducing allergic inflammation. Although such strategies are successful, they neither cure nor prevent asthma, and, in some cases, have not prevented the disease from progressing [1]. Therefore, new therapeutic strategies must be identified [2]. Studies in mice models of asthma have shed light on the pathophysiology of the disease, and they have enabled us to hypothesize about novel targets for treatment $[3,4]$. The protective nature of endogenous molecules such as prostaglandin (PG) $E_{2}$ provides us with an unusual opportunity to develop research projects aimed at uncovering novel targets. Interest in $\mathrm{PGE}_{2}$ as a clinically beneficial agent in asthma and asthma-like syndromes $[5,6]$ has been rekindled in pre-clinical settings, and has encouraged investigators to further analyze the underlying mechanisms in vitro and in vivo [7-9]. The roles of endogenous $\mathrm{PGE}_{2}$ and of fluctuations in cyclooxygenase (COX)-2 activity in modulating airway reactivity and bronchial inflammation have been investigated in experimental rodent models of asthma by various groups [10,11], including ours $[12,13]$. In addition, we recently reported an improvement in airway inflammation after administration of subcutaneous $\mathrm{PGE}_{2}$ in the murine airway response to house dust mite (HDM) aeroallergens [14]. Our study reproduced observations in humans $[5,6]$ and some of the very recently published data from ovalbumin (OVA)-sensitized mice [7]. Although little is known about the mechanisms involved, our work has also pointed to a $\mathrm{PGE}_{2}$-induced restraining effect on airway mast cell activity as a potentially relevant mediating phenomenon $[13,14]$. These in vivo data build on the results of in vitro experiments in which anti-inflammatory and immunosuppressive actions of $\mathrm{PGE}_{2}$ had been reported. $\mathrm{PGE}_{2}$ has been shown to exert an inhibitory effect on the activity of mast cells $[8,15]$ and to suppress immunological mechanisms such as dendritic [16], and $\mathrm{T}$ [17] cell activation. The findings of our and other groups point to a protective effect of $\mathrm{PGE}_{2}$ involving several stages of asthma progression. A recurrent finding is the effect of $\mathrm{PGE}_{2}$ on cellular COX expression in vitro [18-20]. This is an area of interest, since the external provision of an endogenous molecule such as a PG might also affect in vivo the balance of the internal system of COX-2-PGE 2 -EP, and such an effect on the endogenous COX pathway possibly contributes to the clinical benefit resulting from administration of $\mathrm{PGE}_{2}$. Similarly, the $\mathrm{PGE}_{2}$-induced fluctuation of $\mathrm{E}$ prostanoid (EP) receptor ( $\mathrm{PGE}_{2}$ receptor) expression shown in vitro $[21,22]$, may have a profound impact on the ability of exogenous $\mathrm{PGE}_{2}$ to modulate the murine airway response to HDM. The EP3 receptor may be a main candidate for protection [23]. Despite its interest, the functional consequences on the COX-2-PGE 2 -EP receptor pathway of administering $\mathrm{PGE}_{2}$ in vivo remains largely unknown. This gap is probably partly attributable to the lack of accurate data on the fluctuating activity of the endogenous COX system in aeroallergen-induced asthma. Therefore, the direction, the relevance, and the implications of the fluctuations of different elements of the COX pathway need to be ascertained as a whole in an in vivo system.

We used HDM-sensitized mice, whose unique features enable us to mimic the development of allergic asthma in humans, to characterize in vivo the COX-2-PGE 2 -EP pathway. Under the hypothesis that $\mathrm{PGE}_{2}$-driven changes in airway inflammation are also attributable to fluctuations in the internal functioning of this axis, we proceeded to evaluate how expression of COX-2, PG, and EP were affected by the administration of $\mathrm{PGE}_{2}$.

\section{Methods \\ HDM-sensitive mice and experimental groups}

Samples from mice sensitized to HDM aeroallergens that had been shown to develop airway hyperreactivity and inflammation [14], were used in the present study. Briefly, eight-week-old female BALBc mice (Harlan, Spain) housed under a 12-hour light-dark cycle, had been exposed to a purified HDM extract (Alk-Abelló, Madrid, Spain) with a low lipopolysaccharide (LPS) content $(<0.5$ EU/dose, measured using the Charles River Endosafe Limulus Amebocyte Assay, Charles River Laboratories, Wilmington, Massachusetts, USA). The allergen was administered intranasally at a dose of $25 \mu \mathrm{g} /$ mouse in a $10 \mu$ volume for 10 consecutive days. Immediately before administration of HDM, light anesthesia was induced in a chamber filled with $4 \%$ halothane delivered over a period of 2 minutes in 100\% oxygen and maintained for 2 additional minutes with $2.5 \%$ halothane. Non-sensitized (control) animals were handled identically, except that they received intranasal saline instead of HDM extract.

Six experimental groups were established. The first 3 groups contained non-sensitized (control) mice: group 1 contained untreated mice $(n=15)$ and groups 2 and 3 contained $\mathrm{PGE}_{2}$-treated $(\mathrm{n}=15)$ and sulprostone-treated $(n=5)$ animals, respectively. The remaining 3 groups contained HDM-sensitized mice: group 4 included untreated animals $(\mathrm{n}=21)$, and groups 5 and 6 contained $\mathrm{PGE}_{2}-$ treated $(n=21)$ and sulprostone-treated $(n=11)$ animals, respectively. All animal procedures were approved by the Ethics Committee for Animal Research of the Universitat Autònoma de Barcelona.

\section{Administration of subcutaneous $P G E_{2}$ and sulprostone}

Both HDM-sensitized and non-sensitized mice had been treated with either $\mathrm{PGE}_{2}(0.5 \mathrm{mg} / \mathrm{kg})$ or sulprostone $(80$ $\mu \mathrm{g} / \mathrm{kg}$ ), an EP3 agonist with a slight EP1 effect. Both EP receptor agonists were injected subcutaneously on the 
same day as the HDM extract, although their administration was continued up to day 11 (ie, 2 days after the allergen was withdrawn). The prostanoid treatment was provided 1 hour before exposure to HDM. PGE $_{2}$ was purchased from Cayman (Tallinn, Estonia, ref. 14010) and the solution was prepared daily in phosphate-buffered saline (PBS) from a stock solution dissolved in dimethyl sulfoxide (DMSO) and stored at $-20^{\circ} \mathrm{C}$. The final concentration of DMSO injected was $0.1 \%$. Sulprostone (Cayman, ref. 14765) was also prepared daily in PBS, and the solution administered contained $0.05 \%$ DMSO. The untreated mice underwent the same procedure, except that they received subcutaneous vehicle (PBS containing $0.1 \%$ DMSO) instead of the EP agonist.

\section{Assessment of COX-2 mRNA expression in the lungs}

COX-2 mRNA expression in the lungs was assessed by real time polymerase chain reaction (PCR). After sacrifice, the intermediate lung lobe was kept at $-80^{\circ} \mathrm{C}$ for RNA extraction. Total RNA was extracted using Trireagent (Molecular Research Center Inc, Cincinnati, Ohio, USA), and traces of contaminating genomic DNA were removed using DNAfree (Ambion Inc, Austin, Texas, USA). COX-2 cDNA was generated using MMLV reverse transcriptase (Epicentre, Madison, Wisconsin, USA). For real time-PCR, $2 \mu \mathrm{g}$ of total RNA from each animal was reverse-transcribed and 2 $\mu \mathrm{l}$ of a $1 / 5$ dilution of the resulting cDNA was placed into glass capillaries together with $18 \mu \mathrm{l}$ of a master-mix. The COX-2 primers were designed with PrimerSelect software (DNASTAR Inc, Madison, Wisconsin, USA), and were as follows: forward primer 5'AGCCAGCAAAGCCTAGAGCAACAA3' and reverse primer 5'TGACCACGAGAAACGGAACTAAGAGG3'. PCR was performed in a LightCycler Instrument and the crossing point ( $\mathrm{CP}$, defined as the point at which fluorescence increases appreciably above background fluorescence) was determined by LightCycler software (both from Roche Diagnostics, Mannheim, Germany) using the second derivative maximum method.

\section{Assessment of $P G E_{2}, P G I_{2}$ and $P G D_{2}$ levels in $B A L$ fluid}

After sacrifice, BAL fluid was centrifuged at $400 \mathrm{rcf}$ for 5 minutes at $4^{\circ} \mathrm{C}$ and supernatants were collected and stored at $-80^{\circ} \mathrm{C}$ for analysis. The endogenous production of $\mathrm{PGE}_{2}, 6$-keto $\mathrm{PGF}_{1} \alpha$ (a metabolite of $\mathrm{PGI}_{2}$ ), and $\mathrm{PGD}_{2}$ was determined in BAL fluid using a commercial competitive ELISA (Cayman, ref: 514010, 515211, 512021) following the manufacturer's instructions. Briefly, either the standards or the samples were incubated with the tracer antibody, the wells were then washed to remove all unbound reagents, and the signal was developed with Ellman's reagent.

\section{Assessment of $m R N A$ expression EPI, 2, 3, and 4 receptor in the lungs}

mRNA expression of EP receptors 1 to 4 in the lungs was assessed by real-time PCR using TaqMan ${ }^{\circledR}$ Gene Expression Assays containing two unlabeled primers and one 6FAM $^{\mathrm{TM}}$ dye-labeled TaqMan ${ }^{\circledR}$ MGB probe (Applied Biosystems, Foster City, California, USA, ref: Mm00443097_m1, Mm00436051_m1， Mm0.1316856_m1， Mm00436053_m1). Total RNA extraction and contaminating genomic DNA elimination were performed as for the assessment of COX-2 expression. EP1, 2, 3, and 4 cDNA was generated using MMLV reverse transcriptase (Epicentre, Madison, Wisconsin, USA). For real time-PCR, $2 \mu \mathrm{g}$ of total RNA from each animal was reverse-transcribed and $4 \mu \mathrm{l}$ of a $1 / 2$ dilution of the resulting cDNA was placed into a 96-well reaction plate together with 16 $\mu \mathrm{l}$ of the master-mix. The real-time PCR reaction was run on a 7900 HT Real-Time PCR System (Applied Biosystems). The crossing point $(\mathrm{CP}$, defined as the point at which fluorescence increases appreciably above background fluorescence) was determined by 7900 HT RealTime PCR System software (Applied Biosystems) using the second derivative maximum method.

\section{Statistical analysis and calculations}

As for the real time PCR results analysis, the Relative Expression Software Tool (REST ${ }^{\odot}$ ) was applied to calculate the relative expression ratio on the basis of group means for COX-2 or EP receptors (target genes) versus the reference gene GAPDH. The calculated group ratio was tested for significance using a statistical model known as the Pair Wise Fixed Reallocation Randomisation Test ${ }^{\circ}$ [24]. We took into account the PCR efficiency calculated for the target genes (COX-2 and EP1-4) and for GAPDH, which were very similar. As previously published [12], for purposes of graphic representation, the target genes (COX-2 and EP14) mRNA expression ratio of the untreated non-sensitized mice was established as 1.0 , and the average ratios of the other experimental groups were re-calculated on that basis. ELISA PG levels were compared between groups using the $t$ test.

\section{Results \\ Fluctuation of COX-2 pathway activity in the lungs of HDM-sensitized mice}

As shown previously, mice intranasally sensitized to HDM developed significant airway hyperreactivity and eosinophilic inflammation [14] when compared to non-sensitized animals. This reaction was accompanied by changes in the local expression of COX-2, PG, and EP receptors, as depicted by the dark grey bars in Figures 1 through 3. All these COX-2 pathway molecules were determined simultaneously in every single animal, and measurements were performed 48 hours after the last challenge with HDM. COX-2 mRNA expression in the 


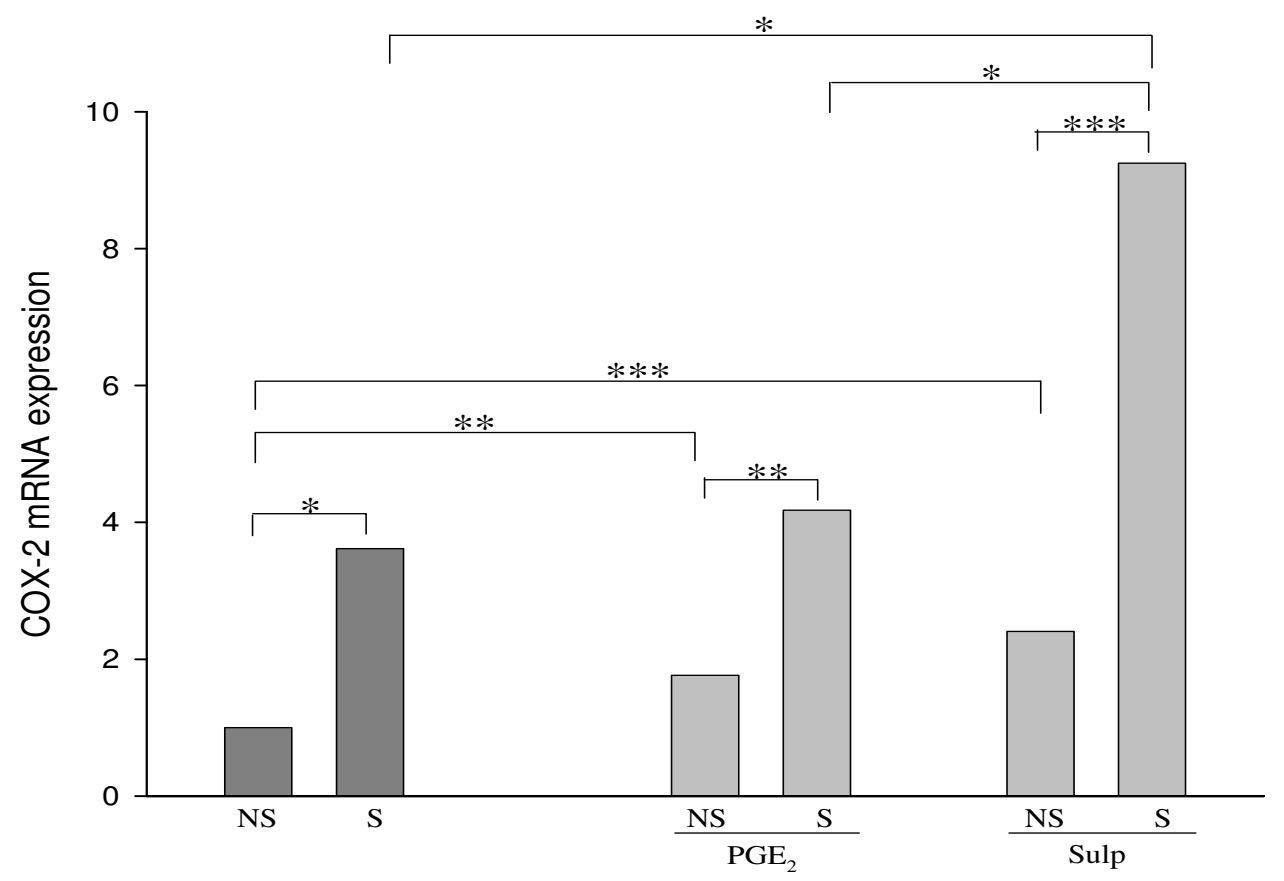

Figure I

Expression of COX-2 mRNA in the lung parenchyma as assayed by real-time PCR. The relative mRNA expression ratio in the non-sensitized (and untreated) mice was established as 1.0. COX-2 mRNA expression in the lungs increased 3.6 fold in HDM-sensitized $(n=I I)$ versus non-sensitized mice $(n=5)$. Baseline levels of COX-2 mRNA in the lungs were higher in non-sensitized mice under both $\operatorname{PGE}_{2}(n=5)$ and sulprostone $(n=5)$ when compared to levels in non-sensitized and nontreated animals. COX-2 expression in $\mathrm{PGE}_{2}(\mathrm{n}=\mathrm{II})$ and sulprostone-treated mice $(\mathrm{n}=\mathrm{II})$ increased by 2.5 and 3.8 fold, respectively, when the animals were exposed to HDM $\left({ }^{*} p<0.05, *_{p}<0.01\right.$, $\left.*^{*} *_{p}<0.005\right)$.

lungs increased 3.6 fold in mice sensitized to HDM aeroallergens compared with non-sensitized mice (Figure 1). COX-2 overexpression in the airways of HDM-sensitized animals was accompanied by a 2.4 -fold increase in the production of both $\mathrm{PGE}_{2}$ (Figure $2 \mathrm{a}$ ) and $\mathrm{PGI}_{2}$ (Figure 2b), but not $\mathrm{PGD}_{2}$ (Figure 2c) in BAL fluid. The mRNA expression of $\mathrm{PGE}_{2}$ receptors EP 1 to 4 was also determined in lung extracts (Figure 3). Despite higher levels of mRNA in all four receptors in HDM-sensitized mice than in non-sensitized mice, only EP2 showed a statistically significant allergen-induced upregulation in HDM-sensitized mice - 4.6-fold (Figure 3b).

\section{Effect of exogenous $P G E_{2}$ on airway COX-2 and $P G$ expression in HDM-sensitized and non-sensitized mice} As previously reported [14], subcutaneous $\mathrm{PGE}_{2}$, but not sulprostone, significantly reduced HDM-induced eosinophil recruitment into the airways (by approximately $40 \%$ ), but had no effect on methacholine-induced airway hyperreactivity. In these animals, the effect of exogenous $\mathrm{PGE}_{2}$ and sulprostone on airway COX-2 activity was measured by evaluating COX-2 mRNA expression in parallel to the BAL COX-2 products $\mathrm{PGE}_{2}, \mathrm{PGI}_{2}$, and $\mathrm{PGD}_{2}$. Baseline levels of lung COX-2 mRNA in non-sensitized mice were significantly increased under both the $\mathrm{PGE}_{2}$ (1.8-fold increase) and the sulprostone (2.4-fold increase) treatment when compared with levels in non-sensitized or non-treated animals (Figure 1). As observed in nontreated sensitized animals, COX-2 expression in $\mathrm{PGE}_{2}$ and sulprostone-treated mice increased when these mice were sensitized to HDM allergens. The magnitude of this increase was 2.5 fold and 3.8 fold for mice under $\mathrm{PGE}_{2}$ and sulprostone, respectively.

As for airway COX-2 product synthesis, HDM-induced enhanced endogenous $\mathrm{PGE}_{2}$ production returned to baseline values in sensitized animals treated with exogenous $\mathrm{PGE}_{2}$. This effect was uncovered by the significant difference in $\mathrm{PGE}_{2}$ levels in BAL between sensitized non-treated and $\mathrm{PGE}_{2}$-treated mice (Figure $2 \mathrm{a}$ ). However, sulprostone did not reduce endogenous $\mathrm{PGE}_{2}$ production in HDMsensitized mice. Similarly, the increase in $\mathrm{PGI}_{2}$ in BAL in HDM-sensitized mice was lower after administration of external $\mathrm{PGE}_{2}$ (Figure 2b). Sulprostone had a similar inhibitory effect on $\mathrm{PGI}_{2}$ production. Finally, $\mathrm{PGD}_{2}$ was not significantly affected by treatment with either agonist (Figure 2c). 


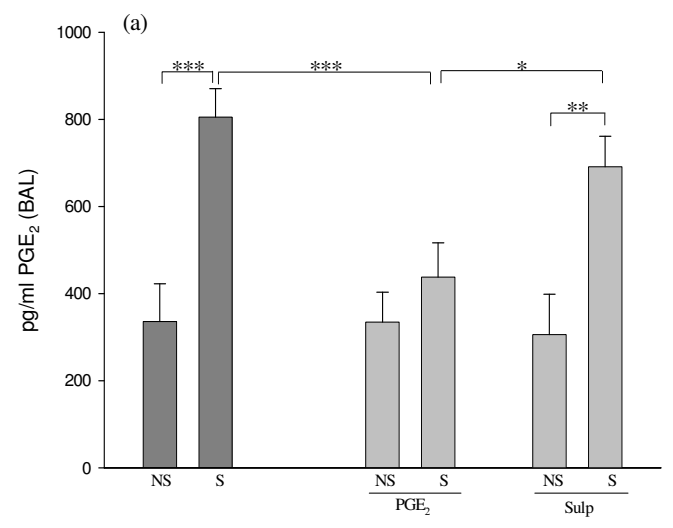

(b)
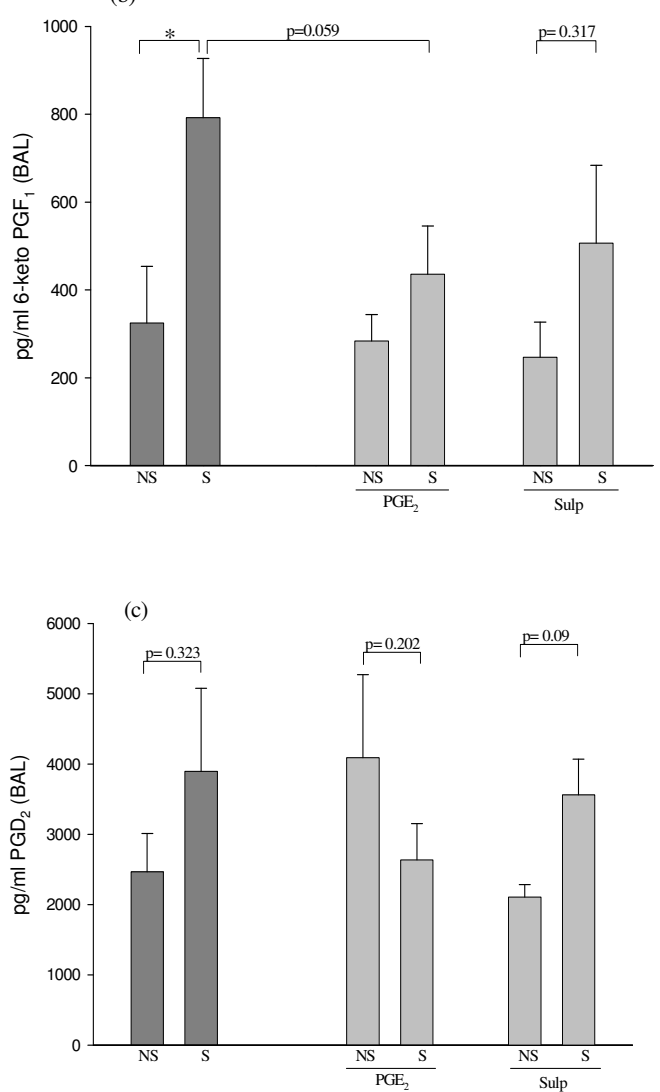

Figure 2

Endogenous prostaglandin production in the airways as assayed by ELISA in BAL fluid. Graph (a) shows endogenous $P G E_{2}$ production. $P E_{2}$ increased 2.4 fold in allergen-sensitized $(n=I I)$ versus non-sensitized mice $(n=5)$. Endogenous $\mathrm{PGE}_{2}$ production fell significantly to baseline levels in HDM-sensitized mice treated with $\mathrm{PGE}_{2}(\mathrm{n}=\mathrm{II})$, but remained unchanged when mice were treated with sulprostone $(n=I I)$. Graph $(b)$ depicts endogenous airway 6-keto PGF $\alpha$ production (a metabolite of $P G I_{2}$ ). In the same way as $P G E_{2}, 6-k e t o P^{2} F_{1} \alpha$ increased 2.4 fold in allergen-sensitized $(n=1 \mathrm{I})$ versus nonsensitized mice $(n=5)$. 6-keto $P_{G F} \alpha$ production fell in HDM-sensitized mice treated with $\mathrm{PGE}_{2}(n=1 \mathrm{I})$ and sulprostone had a similar inhibitory effect on BAL 6-keto PGF $\alpha$ expression $(n=I I)$. Graph (c) shows endogenous PGD 2 production. No differences were found in BAL fluid levels of $\mathrm{PGD}_{2}$ in mice between any of the experimental groups $\left({ }^{*} \mathrm{p}<0.05\right.$, ${ }^{*} \mathrm{p}<0.01$, ***p $<$ 0.005). 
(a)

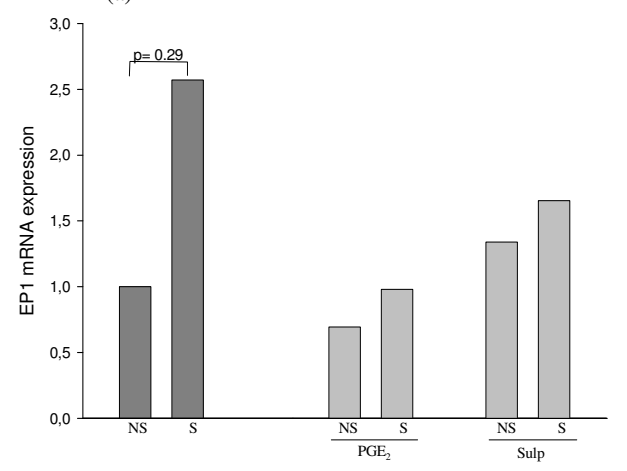

(c)

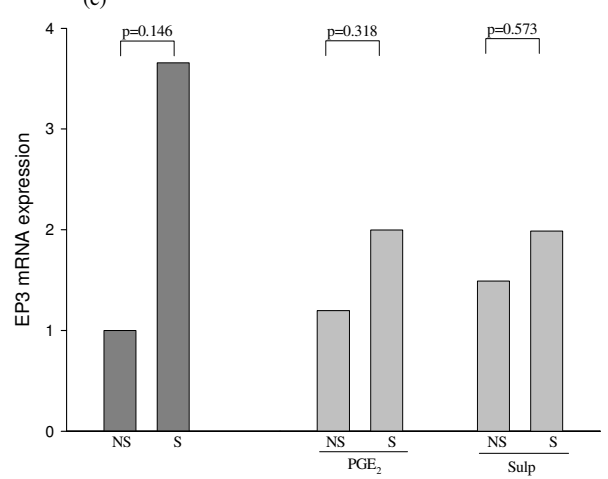

(b)
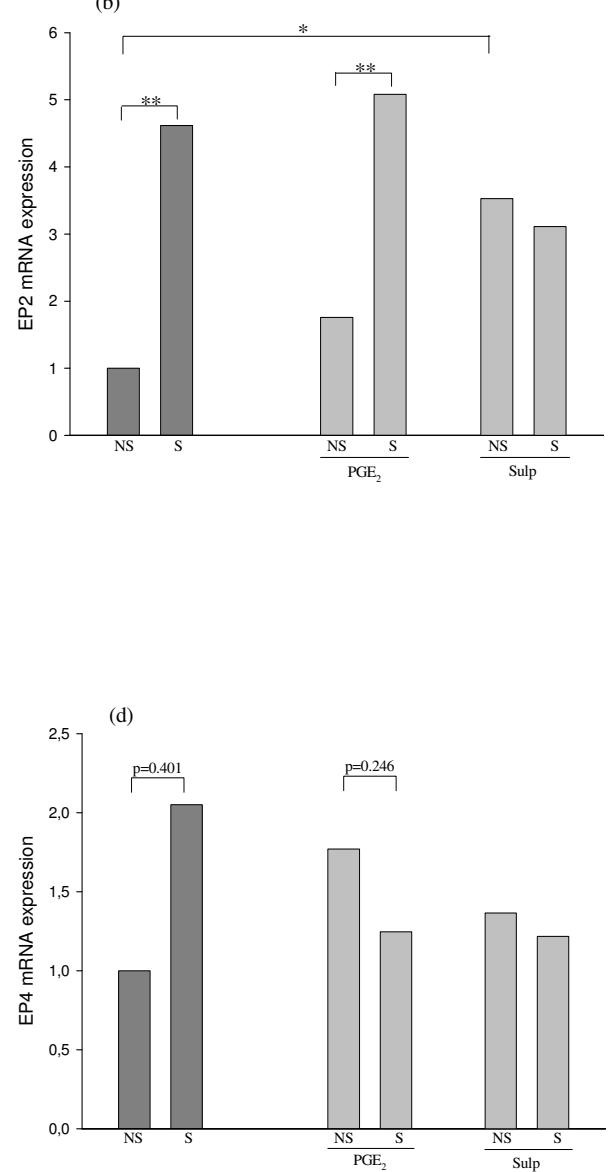

\section{Figure 3}

Relative expression of EP I, 2, 3 and 4 receptors mRNA in lung tissue assayed by real-time PCR. Graphs a, b, c, and $d$ show the mRNA expression of the EPI, EP2, EP3, and EP4 receptors, respectively, in the different treatment groups. EP receptor mRNA expression was higher for all four receptors in HDM-sensitized mice $(n=I I)$ than in non-sensitized animals $(n$ $=5$ ), but only EP2 showed a significant allergen-induced upregulation (4.6 fold). Treatment with either agonist (PGE ${ }_{2}$ or sulprostone) did not significantly alter the level of expression of lung EPI, 3 , and 4 in non-sensitized $(n=5)$ or HDM-sensitized mice $(n=1 \mathrm{I})$. However, sulprostone, but not $\mathrm{PGE}_{2}$, induced a 3.5-fold increased expression of EP2 baseline levels (non-sensitized mice), and it then prevented HDM from further enhancing these levels $\left(*_{p}<0.05\right.$, $\left.*^{*} p<0.0 \mathrm{l}\right)$.

\section{Effect of exogenous $P G E_{2}$ on EP receptor expression in the lungs of HDM-sensitized mice}

Figure $3 a, b, c$, and $3 d$ depict the effect of $\mathrm{PGE}_{2}$ and sulprostone on lung EP receptors 1, 2, 3, and 4 mRNA expression, respectively. Treatment with either agonist did not significantly alter the level of expression of lung EP1, 3, or 4 in either baseline (non-sensitized) or HDM-sensitized mice from a statistical perspective. However, as for HDMinduced EP2 overexpression in sensitized mice, sulprostone, but not $\mathrm{PGE}_{2}$, prevented upregulation at 2 different levels: it induced a 3.5-fold increase in the baseline expression of EP2, and it prevented HDM from further enhancing this baseline level.

\section{Discussion}

We have shown that, in addition to inducing airway hyperreactivity and eosinophil recruitment, intranasal exposure to HDM alters the endogenous COX-2 pathway at various levels: it upregulates COX-2, $\mathrm{PGE}_{2}$, and $\mathrm{PGI}_{2}$ in the lungs, and it enhances local $\mathrm{EP}_{2}$ receptor expression. Exogenous $\mathrm{PGE}_{2}$ modulates these HDM-induced changes in the COX2/PG/EP receptor pathway. Notably, in addition to reducing airway eosinophilia, it prevents HDMinduced lung $\mathrm{PGE}_{2}$ and $\mathrm{I}_{2}$ overexpression, but does not counteract HDM aeroallergens-induced $\mathrm{EP}_{2}$ upregulation.

Lung COX-2 mRNA expression and generation of its product $\mathrm{PGE}_{2}$, are increased in HDM-sensitized mice. Interestingly, a similar pattern is observed with $\mathrm{PGI}_{2}$, another 
anti-inflammatory PG [25], but not with $\mathrm{PGD}_{2}$. We know that COX-2 upregulation is tightly linked to PGE synthase (PGES-1) activity [26]. In turn, although $\mathrm{PGI}_{2}$ was traditionally considered to derive mainly from COX-1, in the last few years this paradigm has proven to be incorrect, since studies in mice and humans have shown that COX2 is the dominant source of $\mathrm{PGI}_{2}$ [26]. The fluctuations of $\mathrm{PGE}_{2}$ and $\mathrm{PGI}_{2}$ are therefore possibly the result of enhanced expression of COX-2. As far as we know, ours is the first report to demonstrate aeroallergen-induced modulation of the complete COX-2 pathway. This builds on our previous results [12], in which we detected a trend towards increased COX-2 and $\mathrm{PGE}_{2}$ activity in the lungs of HDM-sensitized mice, and on an earlier report in which OVA-sensitized guinea pigs were used [27]. It is difficult to uncover the significance of aeroallergen-induced increased lung COX-2 production. According to our and others hypothesis, asthma develops partly as a result of improper regulation of COX-2 activity $[28,29]$, and, given that $\mathrm{PGE}_{2}$ and $\mathrm{PGI}_{2}$ are considered anti-inflammatory protective prostanoids within the lungs $[25,30]$, we speculate that $\mathrm{PGE}_{2}$ and $\mathrm{PGI}_{2}$, but not $\mathrm{PGD}_{2}$, attempt to trigger a beneficial compensatory phenomenon in mice exposed to HDM. Although this concept has yet to be proven, our in vivo data confirm in vitro findings where the overactivity of the COX-2/PGE $2 / \mathrm{EP}_{2}$ pathway was viewed as an effort to minimize allergen-induced damage $[18,31]$. This idea is reinforced by the fact that airway pathology worsens when endogenous $\mathrm{PGE}_{2}$ is presumably inhibited either genetically or pharmacologically in antigen-sensitized mice, as shown by ours [13] and other groups [10,11].

$\mathrm{PGD}_{2}$, in turn, has traditionally been described as a PG inducing functional exacerbation of the airways, despite the fact that recent articles report a potentially beneficial effect [32,33]. In our view, the unchanged levels of $\mathrm{PGD}_{2}$ in our setting two days after the last allergen challenge could be attributable to timing issues, i.e. $\mathrm{PGD}_{2}$ probably peaks immediately after challenge. If so, a different experimental time-course approach would be required to reveal such $\mathrm{PGD}_{2}$ fluctuations in the HDM mouse model.

Data on whether COX-2, $\mathrm{PGE}_{2}$ and/or $\mathrm{PGI}_{2}$ are overproduced or not in the lungs of asthmatics are contradictory. Several authors have described either upregulation, or downregulation and even unchanged levels [28,29,3437]. These contradictions could timing-related [38] or be genetically determined; in any case, they reflect the complexity of understanding COX-2/PG dynamics in the lungs of asthmatics and confirm the need for an experimental in vivo approach to identify the actual changes and their clinical impact. The genetic basis is a fundamental issue, since it has been hypothesized that the COX-2 gene might be altered in asthmatics [28,29,38]. This potential human genetic defect does not affect mice and this probably explains why in our study the animals remain fully able to respond with consistent COX-2 activity increases when exposed to aeroallergens.

In addition to COX-2 and $\mathrm{PGE}_{2}$, intranasal HDM selectively increases EP2 receptor expression in the lungs of mice. It is worth noting that increases in mRNA levels were detected in all four receptors, but that statistical significance was only reached with EP2. The lack of statistical significance in EP1, 3 and 4 is probably attributable to interindividual variability of endogenous molecules expression and to the nature of the mRNA detection system. Despite such technical limitations, EP2 overexpression was shown to be consistent and statistically significant. This would suggest that EP2 uregulation is a relevant trait of an internal defensive strategy of the COX$2 / \mathrm{PGE}_{2} / \mathrm{EP}$ pathway against HDM aeroallergens aggression, but such statement requires further experimental evidence. Our hypothesis on a leading anti-inflammatory role of EP2 in HDM-sensitive mice would agree with findings from in vitro experimental approaches where EP2 was proposed a candidate receptor to mediate the beneficial effects of $\mathrm{PGE}_{2}$ in humans $[7,8,15]$. Although not reported from in vivo experiments in mice models, a selective upregulation of EP2 has been described by Burgess JK et al. [31] in airway smooth muscle cells from asthmatics. All in all, an internal EP2-mediated compensatory mechanism aimed at reducing the damage induced by HDM in animals whose COX-2/PG armamentarium is genetically intact seems to be a reasonable explanation. In order to ascertain the relevance of a selective EP2 increase in attenuating airway pathology, EP2 receptor genetic manipulation (e.g. antisense oligonucleotide or iRNA) would be required.

A recent report by our group [14] showed that $\mathrm{PGE}_{2}$ significantly reduced to almost a half HDM-induced airway eosinophilia, but had no effect on AHR. An intensive single-dose treatment protocol with the agonists starting a day before the actual exposure to HDM was used with the purpose of ensuring that effective prostanoid levels would be present during the relevant phases of the process, regardless of the clinical relevance of such concentrations. The early treatment with the EP agonists was also partly based on the reported immuosuppressive effects of PGE2 in vitro $[16,17]$. We have now observed that, under this protocol, in parallel to preventing eosinophil recruitment, exogenous $\mathrm{PGE}_{2}$ clearly attenuates endogenous production of $\mathrm{PGE}_{2}$ and $\mathrm{PGI}_{2}$. Lung COX-2 expression, if at all, is only very slightly affected and certainly not to the extent of the change in PG production. A straightforward explanation would be that exogenous $\mathrm{PGE}_{2}$ overtakes the role exerted by the endogenous PG, with no need to maintain a similar endogenous production of $\mathrm{PGE}_{2}$ and $\mathrm{PGI}_{2}$, since an external source of $\mathrm{PGE}_{2}$ is already provided. This would 
therefore be viewed as a classical negative feedback mechanism, possibly on the PG synthases rather than COX-2. Alternatively, the reduced PG expression in the presence of exogenous PGE2 might be the result of less infiltrated inflammatory cells producing such PG within the airways.

Sulprostone neither reduces inflammation nor alters the HDM-induced increase in COX-2 or $\mathrm{PGE}_{2}$ levels. It does exert some effect on the level of COX-2 mRNA expression, although such an effect is similar in HDM-sensitized and non-sensitized animals. Therefore, this phenomenon does not selectively occur in allergen-sensitized mice. This somehow shows that EP1/EP3 and EP2 (and possibly EP4) are independent systems, and confirms that $\mathrm{PGE}_{2}$ anti-inflammatory activity in HDM aeroallergens-induced airway pathology in mice is more likely the result of an EP2-mediated effect as discussed earlier. To confirm this hypothesis further experiments with an EP2 selective agonist are required. Interestingly, the analysis of airway EP receptor expression in the presence of EP receptor agonists brings us to a similar conclusion. Exogenous $\mathrm{PGE}_{2}$ does not prevent the HDM-induced increase in EP2, but sulprostone does. Given the observed anti-inflammatory nature of $\mathrm{PGE}_{2}$ (but not sulprostone) [14], this supports the assertion that the increase in EP2 is necessary in mediating the anti-inflammatory effect of $\mathrm{PGE}_{2}$. Furthermore, our data suggest that an EP2 agonist, whether exogenous or endogenous, is needed to keep EP2 levels raised. Finally, it is noteworthy that lung levels of EP2 are similar in HMD-sensitized mice regardless whether they are treated or not with $\mathrm{PGE}_{2}$, and yet $\mathrm{PGE}_{2}$-treated mice do have lower numbers of eosinophils in the airways [14]. This suggests that exogenously delivered $\mathrm{PGE}_{2}$ peaks (undetected by ELISA) are necessary for protection simultaneously to the overexpression of EP2.

\section{Conclusion}

In summary, we can infer that exposure to HDM aeroallergens in mice boosts the COX-2-PGE 2 -EP2 pathway, possibly to alleviate progression of asthma. This effect counterbalances HDM-induced damage by selectively incrementing the interaction of $\mathrm{PGE}_{2}$ with its EP2 receptor. The exogenous provision of $\mathrm{PGE}_{2}$ precludes endogenous counterparts from augmenting but helps sustain high levels of EP2. This is the first report to characterize the complete lung COX-2 pathway in vivo in a mouse model of asthma including enzyme expression, PG production, and $\mathrm{PGE}_{2}$ receptor expression. Given the complexity of the multiple effects of $P G$, a time-course variable needs to be incorporated into such studies to assess the fluctuating activity of the endogenous COX-2 pathway in HDM-sensitized mice, whether treated with $\mathrm{PGE}_{2}$ or not, with the final aim of proposing potential targets for pharmacological development.

\section{Competing interests}

The authors declare that they have no competing interests.

\section{Authors' contributions}

FDM obtained funding for the project, provided overall guidance for the study, assisted in the analysis and interpretation of the data, and prepared the manuscript. AH participated in the experimental design, planned and performed all of the experiments, and helped in the writing of the manuscript. RT, MS, and LP participated in sample and data collection, and helped in the revision of the manuscript. CP participated in the acquisition of funding, designing the experiments, and revising the manuscript. All the authors have read and approved the final manuscript.

\section{Acknowledgements}

We would like to thank the following people: Dr. Domingo Barber and Dr. Enrique Perlado from Alk-Abelló, Madrid, Spain, for providing the HDM extract, and Ms. Mireya Fuentes and Mr. Pere Losada for their valuable technical contribution to the experiments.

This study was supported by a grant from Fondo de Investigación Sanitaria (Ref. PI060592) managed by the Instituto de Salud Carlos III of the Spanish Ministry of Health, and by a fellowship from Fundació Catalana de Pneumologia (FUCAP) awarded to junior members of the team.

\section{References}

I. Peters SP, Ferguson G, Deniz Y, Reisner C: Uncontrolled asthma: a review of the prevalence, disease burden and options for treatment. Respir Med 2006, 100(7): I |39-II5I.

2. Holgate $S$, Bisgaard $H$, Bjermer L, Haahtela T, Haughney J, Horne R, Mclvor A, Palkonen S, Price DB, Thomas M, Valovirta E, Wahn U: The Brussels Declaration: the need for change in asthma management. Eur Respir J 2008, 32(6): I433-1442.

3. Finkelman FD, Wills-Karp M: Usefulness and optimization of mouse models of allergic airway disease. J Allrgy Clin Immunol 2008, I 21:603-606.

4. Yang G, Li L, Volk A, Emmell E, Petley T, Giles-Komar J, Rafferty P, Lakshminarayanan M, Griswold DE, Bugelski PJ, Das AM: Therapeutic dosing with anti-interleukin- 13 monoclonal antibody inhibits asthma progression in mice. J Pharmacol Exp Ther 2005, 313(I):8-15.

5. Huang SK, Peters-Golden M: Eicosanoid lipid mediators in fibrotic lung diseases. Chest 2008, I33(6): I 442- I 450.

6. Gauvreau GM, Watson RM, O'Byrne PM: Protective effects of inhaled PGE2 on allergen-induced airway responses and airway inflammation. Am J Respir Crit Care Med 1999, I 59:31-36.

7. Sturm EM, Schratl P, Schuligoi R, Konya V, Sturm G], Lippe IT, Peskar BA, Heinemann A: Prostaglandin E2 inhibits eosinophil trafficking through E-prostanoid 2 receptors. J Immunol 2008, I81(10):7273-7283.

8. Kay LJ, Yeo WW, Peachell PT: Prostaglandin E2 activates EP2 receptors to inhibit human lung mast cell degranulation. $\mathrm{Br}$ J Pharmacol 2006, I47(7):707-7|3.

9. De Campo BA, Henry PJ: Stimulation of protease-activated receptor-2 inhibits airway eosinophilia, hyperresponsiveness and bronchoconstriction in a murine model of allergic inflammation. BrJ Pharmacol 2005, I44: I I00-I I08.

10. Peebles RS], Hashimoto K, Morrow JD, Dworski R, Collins RD, Hashimoto Y, Christman JW, Kang KH, Jarzecka K, Furlong J, Mitchell DB, Talati M, Graham BS, Sheller JR: Selective cyclooxygenase-I and -2 inhibitors each increase allergic inflammation and airway hyperresponsiveness in mice. Am J Respir Crit Care Med 2002, 165:1154-1160.

II. Gavett SH, Madison SL, Chulada PC, Scarborough PE, Qu W, Boyle JE, Tiano HF, Lee CA, Langenbach R, Roggli VL, Zeldin DC: Allergic 
lung responses are increased in prostaglandin $\mathbf{H}$ synthasedeficient mice. J Clin Invest 1999, 104:721-732.

12. Torres R, Herrerias A, Serra M, Roca-Ferrer J, Pujols L, Marco A, Picado $C$, de Mora F: An intranasal selective antisense oligonucleotide impairs lung cyclooxygenase-2 production and improves inflammation, but worsens airway function, in house dust mite sensitive mice. Respir Res 2008, 9(I):72.

13. Torres R, Pérez M, Marco A, Picado C, de Mora F: A cyclooxygenase-2 selective inhibitor, worsens respiratory function and enhances mast cells activity in a murine model of allergic asthma. Arch Bronconeumol 45(4):162-7.

14. Herrerias A, Torres R, Serra M, Marco A, Roca-Ferrer J, Picado C, de Mora F: Subcutaneous prostaglandin $E_{2}$ restrains airway mast cell activity in vivo and reduces airway eosinophilia and lung $\mathrm{Th}_{2}$ cytokine overproduction in a house dust mite-induced mouse model of asthma. Int Arch Allergy Immunol 2009, I49(4):323-332

15. Duffy SM, Cruse G, Cockerill SL, Brightling CE, Bradding P: Engagement of the EP2 prostanoid receptor closes the K+ channel $\mathrm{KCa} 3 . \mathrm{I}$ in human lung mast cells and attenuates their migration. Eur J Immunol 2008, 38(9):2548-2556.

16. Son $Y$, Ito T, Ozaki Y, Tanijiri T, Yokoi T, Nakamura K, Takebayashi $\mathrm{M}$, Amakawa R, Fukuhara S: Prostaglandin E2 is a negative regulator on human plasmacytoid dendritic cells. Immunology 2006, I I 9 (I):36-42.

17. Okano M, Sugata $Y$, Fujiwara T, Matsumoto R, Nishibori M, Shimizu K, Maeda M, Kimura Y, Kariya S, Hattori H, Yokoyama M, Kino K, Nishizaki K: E prostanoid 2 (EP2)/EP4-mediated suppression of antigen-specific human T-cell responses by prostaglandin E2. Immunology 2006, I I 8(3):343-352.

18. Bonazzi A, Bolla M, Buccellati C, Hernandez A, Zarini S, Viganò T, Fumagalli F, Viappiani S, Ravasi S, Zannini P, Chiesa G, Folco G, Sala $A$ : Effect of endogenous and exogenous prostaglandin $E(2)$ on interleukin-I beta-induced cyclooxygenase- 2 expression in human airway smooth-muscle cells. Am J Respir Crit Care Med 2000, 162(6):2272-2277.

19. Hinz B, Brune K, Pahl A: Prostaglandin E(2) upregulates cyclooxygenase-2 expression in lipopolysaccharide-stimulated RAW 264.7 macrophages. Biochem Biophys Res Commun 2000, 272(3):744-748.

20. Lo CJ, Chiu KC, Fu M, Lo R, Helton S: Fish oil augments macrophage cyclooxygenase II (COX-2) gene expression induced by endotoxin. J Surg Res 1999, 86(I): 103-107.

21. Weinreb M, Machwate M, Shir N, Abramovitz M, Rodan GA, Harada $S$ : Expression of the prostaglandin $E(2)$ (PGE(2)) receptor subtype $E P(4)$ and its regulation by $P G E(2)$ in osteoblastic cell lines and adult rat bone tissue. Bone 200I, 28(3):275-28I.

22. Yun SP, Lee MY, Ryu JM, Han HJ: Interaction between PGE2 and EGF receptor through MAPKs in mouse embryonic stem cell proliferation. Cell Mol Life Sci 2009, 66(9): 1603-16.

23. Kunikata T, Yamane H, Segi E, Matsuoka T, Sugimoto Y, Tanaka S, Tanaka H, Nagai H, Ichikawa A, Narumiya S: Suppression of allergic inflammation by the prostaglandin $E$ receptor subtype EP3. Nat Immunol 2005, 6(5):524-3I.

24. Pfaffl MW, Horgan GW, Dempfle L: Relative expression software tool (REST) for group-wise comparison and statistical analysis of relative expression results in real-time PCR. Nucleic Acids Res 2002, 30(9): 36 .

25. Jaffar Z, Wan KS, Roberts K: A key role for prostaglandin $\mathbf{1 2}$ in limiting lung mucosal Th2, but not ThI, responses to inhaled allergen. J Immunol 2002, I69( I 0):5997-6004.

26. Cipollone F, Cicolini G, Bucci M: Cyclooxygenase and prostaglandin synthases in atherosclerosis: recent insights and future perspectives. Pharmacol Ther 2008, I I 8(2):161-|80.

27. Oguma T, Asano K, Shiomi T, Fukunaga K, Suzuki Y, Nakamura M, Matsubara H, Sheldon HK, Haley KJ, Lilly CM, Drazen JM, Yamaguchi $\mathrm{K}$ : Cyclooxygenase-2 expression during allergic inflammation in guinea-pig lungs. Am J Respir Crit Care Med 2002, 165(3):382-386.

28. Chambers LS, Black JL, Ge Q, Carlin SM, Au WW, Poniris M, Thompson J, Johnson PR, Burgess JK: PAR-2 activation, PGE2, and COX-2 in human asthmatic and nonasthmatic airway smooth muscle cells. Am J Physiol Lung Cell Mol Physiol 2003, 285:L619-L627.

29. Picado C, Bioque G, Roca-Ferrer J, Pujols L, Mullol J, Benitez P, Bulbena $O$ : Nuclear factor-kappaB activity is down-regulated in nasal polyps from aspirin-sensitive asthmatics. Allergy 2003 , 58:122-126.

30. Vancheri $C$, Mastruzzo $C$, Sortino MA, Crimi N: The lung as a privileged site for the beneficial actions of PGE2. Trends in Immunol 2004, 25(I):40-46.

31. Burgess JK, Ge Q, Boustany S, Black JL, Johnson PR: Increased sensitivity of asthmatic airway smooth muscle cells to prostaglandin E2 might be mediated by increased numbers of Eprostanoid receptors. J Allergy Clin Immunol 2004, I I 3(5):876-88 I.

32. Oguma T, Asano K, Ishizaka A: Role of Prostaglandin D(2) and its receptors in the pathophysiology of asthma. Allergol Int 2008, 57(4):307-3I 2.

33. Shiraishi $Y$, Asano K, Nakajima T, Oguma T, Suzuki Y, Shiomi T, Sayama K, Niimi K, Wakaki M, Kagyo J, Ikeda E, Hirai H, Yamaguchi $\mathrm{K}$, Ishizaka A: Prostaglandin D2-induced eosinophilic airway inflammation is mediated by CRTH2 receptor. J Pharmacol Exp Ther 2005, 3 | 2(3):954-60.

34. Profita M, Sala A, Bonanno A, Riccobono L, Siena L, Melis MR, D Giorgi R, Mirabella F, Gjomarkaj M, Bonsignore G, Vignola AM: Increased prostaglandin E2 concentrations and cyclooxygenase-2 expression in asthmatic subjects with sputum eosinophilia. J Allergy Clin Immunol 2003, I I 2(4):709-7I6.

35. Pierzchalska M, Szabó Z, Sanak M, Soja J, Szczeklik A: Deficient prostaglandin E2 production by bronchial fibroblasts of asthmatic patients, with special reference to aspirin-induced asthma. J Allergy Clin Immunol 2003, I I I (5): I04 I- 1048.

36. Wenzel SE, Westcott JY, Smith HR, Larsen GL: Spectrum of prostanoid release after bronchoalveolar allergen challenge in atopic asthmatics and in control groups. An alteration in the ratio of bronchoconstrictive to bronchoprotective mediators. Am Rev Respir Dis 1989, I39(2):450-457.

37. Dahlén SE, Hansson G, Hedqvist $P$, Björck $T$, Granström E, Dahlén $B$ : Allergen challenge of lung tissue from asthmatics elicits bronchial contraction that correlates with the release of leukotrienes C4, D4, and E4. Proc Natl Acad Sci USA 1983, 80(6): $17|2-17| 6$.

38. Pujols L, Mullol J, Alobid I, Roca-Ferrer J, Xaubet A, Picado C: Dynamics of COX-2 in nasal mucosa and nasal polyps from aspirin-tolerant and aspirin-intolerant patients with asthma. J Allergy Clin Immunol 2004, I I 4(4):8I4-8I9.

\section{Publish with BioMed Central and every scientist can read your work free of charge}

"BioMed Central will be the most significant development for disseminating the results of biomedical research in our lifetime."

Sir Paul Nurse, Cancer Research UK

Your research papers will be:

- available free of charge to the entire biomedical community

- peer reviewed and published immediately upon acceptance

- cited in PubMed and archived on PubMed Central

- yours - you keep the copyright

Submit your manuscript here:

http://www.biomedcentral.com/info/publishing_adv.asp
BioMedcentral 